\title{
A population-based profile of adult Canadians living with participation and activity limitations
}

\author{
Donna Goodridge RN PhD, Josh Lawson MSc PhD, Darcy Marciniuk MD, Donna Rennie RN PhD
}

\begin{abstract}
Background: Currently, one out of every seven Canadians is affected by limitations to their participation and activity. This study describes the self-reported main causes of these limitations in a national sample.

Methods: The 2006 Participation and Activity Limitation Survey was a two-phase stratified survey based on filter questions posed in the 2006 Census of Population conducted by Statistics Canada. Respondents to the survey represent 5185980 Canadian adults with activity and participation limitations. We used these data to develop a profile of our population of interest: adult Canadians with activity and participation limitations. Associations between demographic variables and self-reported causes of activity and participation limitations were assessed using multiple logistic regression.
\end{abstract}

Results: One quarter of participants did not attribute their disability to any medical cause. The most prevalent medical conditions to

$\mathrm{D}$ isabilities affect close to five million, or one in seven, Canadians. ${ }^{1}$ Between 2001 and 2006, the number of Canadians living with a disability increased by $21.2 \%$, rising from $12.4 \%$ to $14.3 \%$ of the population.' Given that the number of adults reporting a disability is expected to continue to rise sharply in the coming years as more people enter the highest-risk age group ( $\geq 65 \mathrm{yr}$ ), the concomitant need for additional and appropriate disability-related health services will exert greater pressure on health care systems. ${ }^{2}$ Data on disabilities are increasingly used to monitor and evaluate public health as a reflection of the burden of health problems in relation to chronic diseases and aging ${ }^{3}$ and to identify the resources needed to ameliorate the impact of disabilities. ${ }^{4}$

"Disablement" was coined by Verbrugge and Jette in $1994^{5}$ to refer to the impacts that chronic and acute conditions have on the functioning of specific body systems and on people's abilities to act in necessary, usual, expected and personally desired ways in society. In 2002, the World Health Organization (WHO) took a broader which disabilities were attributed were musculoskeletal (46.1\%), cardio/cerebrovascular $(12.3 \%)$, mental health $(8.4 \%)$, neurologic $(6.0 \%)$, endocrine $(6.0 \%)$ and respiratory $(4.5 \%)$ conditions. Significant associations were noted between sociodemographic variables and participants' attributions of medical conditions as cause of disability. Multiple logistic regression with bootstrapping showed that people who reported a medical cause for their limitation were more likely $(p<0.05)$ to be female, widowed, 40 years of age or older, born in Canada or white and were less likely $(p<0.05)$ to be in the highest income category or to be employed (i.e., to work more than $0 \mathrm{~h} / \mathrm{w})$.

Interpretation: Most people living with activity and participation limitations report having a musculoskeletal disorder. However, a significant proportion of respondants did not attribute their limitations to a medical cause.

view, defining disability from a biopsychosocial perspective as the interaction between features of the person and features of the context in which he or she lives. ${ }^{4}$ Disability is conceptualized to involve dysfunction at the level of body functions or structures, limitations to activity or restrictions on participation. The International Classification of Functioning, Disability and Health, ${ }^{4}$ is based on an integrated biopsychosocial model and incorporates the following elements under activities and participation: learning and applying knowledge; general tasks and demands; communication; mobility; self care; domestic life; interpersonal interactions and relationships; major life areas; and community, social and civic life. Statistics Canada ${ }^{5,6}$ views disability as an activity limitation or participation restriction associated with long-term physical or mental conditions or health-related conditions. The Statistics Canada definition also incorporates all of the elements listed in the International Classification of Functioning, Disability and Health.

There have been substantial efforts to fight
Competing interests:

Donna Goodridge has received grant funding from the Canadian Institutes of Health Research (CIHR). Darcy Marciniuk is a member of the board for the American College of Chest Physicians, the Chest Foundation, the Canadian Thoracic Society and the Lung Association of

Saskatchewan; he is a consultant for the Saskatoon Health Region, the Public Health Agency of Canada and the Canadian Lung

Assocation; he has received grants from the

Saskatchewan Health Research Foundation and the CIHR. No other competing interests were declared.

This article has been peer reviewed.

Correspondence to: Dr. Donna Goodridge, donna.goodridge@usask.ca

CMAJ 2011. DOI:10.1503 /cmaj.110153 
the automatic identification of disability with illness and to frame disability as a purely social construct. ${ }^{6-8}$ However, many people have participation and activity limitations as a result of chronic illnesses. In addition, many people with participation and activity limitations not caused by illnesses have chronic health problems as a direct result of their restrictions. ${ }^{9}$ Whether a person attributes his or her disability to a medical diagnosis or to another cause has implications for that person's adherence to treatment, selfmanagement and care-seeking behaviours ${ }^{10}$.

Using a validated national sample, this survey study describes the types of medical conditions reported by adult Canadians living with participation and activity limitations.

\section{Methods}

\section{Study design}

We used data from Statistics Canada's 2006 Participation and Activity Limitation Survey ${ }^{10}$ of 38839 adults and 8954 children whose everyday activities are limited because of a health condition or problem. The survey used the WHO definition of disability. ${ }^{4}$ The survey was conducted using a complex survey design with a two-phase stratified sampling plan based on Statistics Canada's 2006 Census of Population. Strata were defined to ensure sufficiently large samples in the domain estimates of province/territory, age and severity of disability. Interviewers completing a computer-assisted questionnaire administered interviews by telephone. Proxy interviews were allowed in situations where an adult respondent was unable to answer the questions over the telephone.

\section{Study population}

A representative sample of people who answered "yes" to the disability filter questions on the census was chosen for participation in our cross-sectional survey. All those who had responded "yes" to any of the following questions were included in the sampling frame: "Do you have any difficulty hearing, seeing, communicating, walking, climbing stairs, bending, learning or doing any similar activities?"; "Does a physical condition, mental condition or health problem reduce the amount or kind of activity you can do at home? At school? In other activities, e.g., transportation or leisure?" From this frame, a sample population was selected for an interview. A subset of the surveyed population who reported disabilities during the interview was considered as the target population for our study. ${ }^{8}$ The Participation and Activity Limitation Survey defines "a person with a disability" ${ }^{\prime}$ as a respondent who answers "yes" to the disability filter question on the census, and who also answers "yes" either to the disability filter questions or to detailed questions on activity limitations in the survey.

The focus of our analysis was people aged 15 years and older residing in private or collective households in Canada's 10 provinces and 3 territories. The survey did not include people living on First Nations reserves or residents of institutional and some noninstitutional collectives (e.g., military bases, Canadian Armed Forces vessels, merchant and coast guard vessels, campgrounds or parks).

\section{Survey data and operational definitions}

Respondents were asked to self-report up to three health conditions in response to the survey question "What are the main medical conditions that cause you the most difficulty or limit your activities?" Data on self-reported health conditions were extracted using the International Statistical Classification of Diseases and Related Health Problems, 10th revision (ICD-10), codes assigned by Statistics Canada. In this paper, we describe the prevalence of the broad categories of disease (ICD-10 chapters) self-reported by participants as causing the most difficulty or limiting activities, as well as the sociodemographic characteristics associated with these categories. The categories we considered include musculoskeletal, cardio/cerebrovascular, mental health, neurologic, endocrine, respiratory, digestive, congenital and dermatologic disorders, cancer and other ailments (injury, falls, poisoning, exposure, vehicular). For a description of these conditions and their definitions according to the ICD-10 codes, see Appendix 1 (available at www.cmaj.ca /lookup/suppl/doi:10.1503/cmaj.110153/-/DC1).

Our sociodemographic variables of interest included sex, ethnic background (white, nonwhite), marital status (married/common law, single/divorced or widowed), level of education (less than high school, high school, more than high school), hours worked per week $(0 \mathrm{~h}, 1-39 \mathrm{~h}$, $\geq 40 \mathrm{~h}$ ); annual income (tertiles based on 2006 Canadian federal personal income tax rates: $\leq 35378, \$ 35378-\$ 72756,>\$ 72756$ ); area of residence (rural $[\leq 1000$ people] or urban $[>1000$ people]), place of birth (within Canada, outside of Canada) and age group ( $<39 \mathrm{yr}, 40-65 \mathrm{yr},>65 \mathrm{yr}$ ).

\section{Statistical analysis}

Statistical models were fitted using purposeful selection where variables were forced into the model for reasons of statistical significance, clinical importance and potential confounding. We used proportions for our descriptive analyses of categorical variables (i.e., the sociodemographic variables). Associations between our sociodemo- 
graphic variables of interest and categories of condition causing limitations were assessed using multiple logistic regression, with the strengths of the associations reported as odds ratios (ORs) with $95 \%$ confidence intervals (CIs). Owing to the complex design of the study, we used bootstrapping to calculate measures of variability, with the dependent variable being whether there was a medical reason provided for the respondent's limitation or the condition responsible for the respondent's limitation. Bootstrapping weights were provided by Statistics Canada.

Our initial analyses included the entire popula- tion within the Participation and Activity Limitation Survey database. However, because of the effect of age when considering adults with participation and activity limitations, we performed secondary analyses after stratification by age group.

All analyses were performed using STATA 9.0 software, and sampling weights were provided by Statistics Canada.

\section{Results}

The total size of the adult ( $\geq 15 \mathrm{yr}$ ) sample from the Participation and Activity Limitation Survey

Table 1: Sociodemographic characteristics of the population represented by respondents to the 2006 Participation and Activity Limitation Survey by age group and overall

\begin{tabular}{|c|c|c|c|c|}
\hline \multirow[b]{2}{*}{ Variable } & \multicolumn{3}{|c|}{ Age group } & \multirow[b]{2}{*}{$\begin{array}{c}\text { Overall, \% } \\
n=5185980\end{array}$} \\
\hline & $\begin{array}{c}\leq 39 \mathrm{yr}, \% \\
n=914700\end{array}$ & $\begin{array}{c}40-65 \mathrm{yr}, \% \\
n=2331040\end{array}$ & $\begin{array}{c}\geq 65 \mathrm{yr}, \% \\
n=1940240\end{array}$ & \\
\hline \multicolumn{5}{|l|}{ Sex } \\
\hline Male & 49.4 & 47.9 & 42.6 & 46.2 \\
\hline Female & 50.6 & 52.1 & 57.4 & 53.8 \\
\hline \multicolumn{5}{|l|}{ Ethnic background } \\
\hline White & 74.4 & 84.7 & 90.5 & 85.1 \\
\hline Nonwhite & 25.6 & 15.3 & 9.5 & 14.9 \\
\hline \multicolumn{5}{|l|}{ Marital status } \\
\hline Married/common law & 39.6 & 67.4 & 54.0 & 57.5 \\
\hline Single/divorced & 60.2 & 28.8 & 11.8 & 28.0 \\
\hline Widowed & 0.2 & 3.8 & 34.2 & 14.5 \\
\hline \multicolumn{5}{|l|}{ Education } \\
\hline$<$ High school & 28.1 & 25.4 & 46.2 & 33.7 \\
\hline High school & 27.2 & 24.0 & 20.1 & 23.1 \\
\hline > High school & 44.7 & 50.6 & 33.6 & 43.2 \\
\hline \multicolumn{5}{|l|}{ Employment, h/w } \\
\hline 0 & 45.6 & 52.4 & 94.9 & 67.1 \\
\hline $1-39$ & 23.2 & 19.0 & 3.1 & 13.8 \\
\hline$\geq 40$ & 31.2 & 28.6 & 2.0 & 19.1 \\
\hline \multicolumn{5}{|l|}{ Annual income } \\
\hline$<\$ 35378$ & 80.4 & 67.7 & 80.2 & 74.6 \\
\hline$\$ 35378-\$ 72756$ & 16.6 & 24.2 & 16.6 & 20.0 \\
\hline$>\$ 72756$ & 3.1 & 8.0 & 3.2 & 5.3 \\
\hline \multicolumn{5}{|l|}{ Residence } \\
\hline Urban & 84.5 & 77.6 & 81.1 & 80.1 \\
\hline Rural & 15.5 & 22.4 & 18.9 & 19.9 \\
\hline \multicolumn{5}{|l|}{ Place of birth } \\
\hline Canada & 78.9 & 75.8 & 69.4 & 73.9 \\
\hline Outside of Canada & 21.1 & 24.2 & 30.6 & 26.1 \\
\hline \multicolumn{5}{|l|}{ Age group, yr } \\
\hline$<39$ & & & & 17.6 \\
\hline $40-65$ & & & & 44.9 \\
\hline$>65$ & & & & 37.4 \\
\hline
\end{tabular}


was 38839 people, representing 5185980 Canadian adults with participation and activity limitations. The overall rate of response for the survey was $74.9 \%$, and the rate of proxy response among people aged 15 years or more was $12.1 \%$. The age groups with the highest rates of proxy response were 15-24 year olds and people aged 75 years and older. Proxy responses were used when respondents were unable to complete the survey themselves (60\%), had a language barrier

Table 2: Characteristics of respondents who provided a medical reason for their activity limitation versus the characteristics of those who did not

\begin{tabular}{|c|c|c|c|}
\hline Characteristic & $\begin{array}{c}\text { Provided no } \\
\text { medical reason } \\
\text { for limitation, \% } \\
n=3894648\end{array}$ & $\begin{array}{c}\text { Provided a } \\
\text { medical reason } \\
\text { for limitation, \% } \\
n=1291332\end{array}$ & $p$ value \\
\hline \multicolumn{4}{|l|}{ Sex } \\
\hline Male (reference) & 51.7 & 44.4 & \\
\hline Female & 48.3 & 55.6 & 0.01 \\
\hline \multicolumn{4}{|l|}{ Ethnic background } \\
\hline White (reference) & 73.6 & 88.7 & \\
\hline Nonwhite & 26.4 & 11.3 & $<0.001$ \\
\hline \multicolumn{4}{|l|}{ Marital status } \\
\hline $\begin{array}{l}\text { Married/common- } \\
\text { law (reference) }\end{array}$ & 60.3 & 56.6 & \\
\hline Single/divorced & 30.7 & 27.1 & 0.62 \\
\hline Widowed & 9.0 & 16.3 & $<0.001$ \\
\hline \multicolumn{4}{|l|}{ Education } \\
\hline $\begin{array}{l}<\text { High school } \\
\text { (reference) }\end{array}$ & 29.9 & 34.9 & \\
\hline High school & 24.3 & 22.7 & 0.54 \\
\hline > High school & 45.8 & 42.4 & 0.21 \\
\hline \multicolumn{4}{|l|}{ Employment, h/w } \\
\hline 0 (reference) & 52.8 & 71.7 & \\
\hline $1-39$ & 16.9 & 12.8 & $<0.001$ \\
\hline$\geq 40$ & 30.3 & 15.5 & $<0.001$ \\
\hline \multicolumn{4}{|l|}{ Annual income } \\
\hline $\begin{array}{l}<\$ 35378 \\
\quad \text { (reference) }\end{array}$ & 70.4 & 76.0 & \\
\hline$\$ 35378-\$ 72756$ & 22.3 & 19.3 & 0.220 \\
\hline$>\$ 72756$ & 7.2 & 4.7 & 0.01 \\
\hline \multicolumn{4}{|l|}{ Residence } \\
\hline Urban (reference) & 81.6 & 79.7 & \\
\hline Rural & 18.4 & 20.3 & 0.40 \\
\hline \multicolumn{4}{|l|}{ Place of birth } \\
\hline Canada (reference) & 64.4 & 77.0 & \\
\hline Outside of Canada & 35.6 & 23.0 & $<0.001$ \\
\hline \multicolumn{4}{|l|}{ Age group, yr } \\
\hline 15-39 (reference) & 27.8 & 14.4 & \\
\hline $40-65$ & 42.5 & 45.7 & $<0.001$ \\
\hline$>65$ & 29.7 & 39.9 & $<0.001$ \\
\hline
\end{tabular}

(14.8\%) or chose to have someone answer the survey on their behalf (i.e., $9.4 \%$ of adolescents and $8.3 \%$ of dependent adults). Most of the respondents who reported participation or activity limitations were white, did not work, earned less than $\$ 35378$ per year, lived in urban areas and were born in Canada (Table 1).

Within our study population, $75.7 \%$ of respondents reported a medical cause for their participation or activity limitation, and people who did so were more likely to be female, white, widowed, born in Canada and older (i.e., > $39 \mathrm{yr}$ ) than people who did not report a medical cause. These respondents were less likely to be employed or in the highest income category (Table 2).

The most prevalent conditions reported as a cause of participation or activity limitation included musculoskeletal, cardio/cerebrovascular, mental health, neurologic, endocrine, and respiratory disorders (Figure 1), and these six categories of conditions are the focus of our remaining analyses. The three most prevalent diagnoses reported in each category are presented in Table 3 .

Comorbidity was present in a substantial proportion of people who reported having any of these six conditions. The highest rate of comorbidity was seen in the endocrine group (77.4\% comorbidity), followed by the cardio/cerebrovascular (67.9\%), respiratory (63.5\%), mental health $(49.9 \%)$, neurologic $(48.5 \%)$ and musculoskeletal (31.5\%) groups.

The prevalences of each of the sociodemographic characteristics for each of the six conditions are reported in Table 4. These results are in agreement with the adjusted associations between sociodemographic factors and reporting a condition as the cause of participation or activity limitations shown in Figure 2 and Appendix 2 (available at www.cmaj.ca/lookup/suppl/doi:10 .1503/cmaj.110153/-/DC1). People who reported a musculoskeletal condition were more likely to be female and older, but they were less likely to be nonwhite, single or divorced, working and born outside of Canada. People who reported cardio/cerebrovascular conditions were more likely to be widowed or older, but they were less likely to be female, have more than a high school education or be working. Among people reporting mental health conditions, there was a greater likelihood of being female (OR 1.33, 95\% CI 1.13-1.58) or being single or divorced (OR 2.19, 95\% CI 1.82-2.64), but a lower likelihood of being nonwhite (OR 0.52 , 95\% CI $0.38-0.70$ ), working (1-39 h/w OR $0.60,95 \%$ CI $0.49-0.73$; $\geq 40 \mathrm{~h} / \mathrm{w}$ OR $0.40,95 \%$ CI $0.31-0.52$ ) earning between $\$ 35378$ and $\$ 62756$ per year (\$35 378-\$72 756 OR 0.67, 95\% CI 0.52-0.85), living in a rural area (OR $0.71,95 \%$ CI 0.58 0.87 ) or being older (age 40-65 yr OR 0.55, 
95\% CI $0.46-0.65$; age $\geq 65$ yr OR $0.09,95 \%$ CI 0.06-0.12). People who reported neurologic conditions were less likely to be nonwhite, working or older. People who reported endocrine conditions were more likely to be nonwhite or older, but they were less likely to be working or to live in a rural area. Finally, people who reported respiratory conditions were less likely to be born outside of Canada.

We performed our analyses again after stratification by age group (Appendix 3, available at www.cmaj.ca/lookup/suppl/doi:10.1503/cmaj .110153/-/DC1.). The associations were typically consistent between age groups, although some notable trends did occur.

As age increased, women were more likely to attribute their limitation to a musculoskeletal condition (Appendix 3).

The inverse association between working $1-$ 39 hours per week and reporting a mental health condition became stronger as age increased (Appendix 3).

Although the protective effect of working at least 40 hours per week on reporting a neurologic condition became stronger as age increased, the protective effect of working 1-39 hours per week on reporting an endocrine condition became weaker as age increased (Appendix 3).

There was a significantly increased risk of reporting neurologic and respiratory conditions for women in the youngest age group (Appendix 3), but a protective effect, which was signifi-

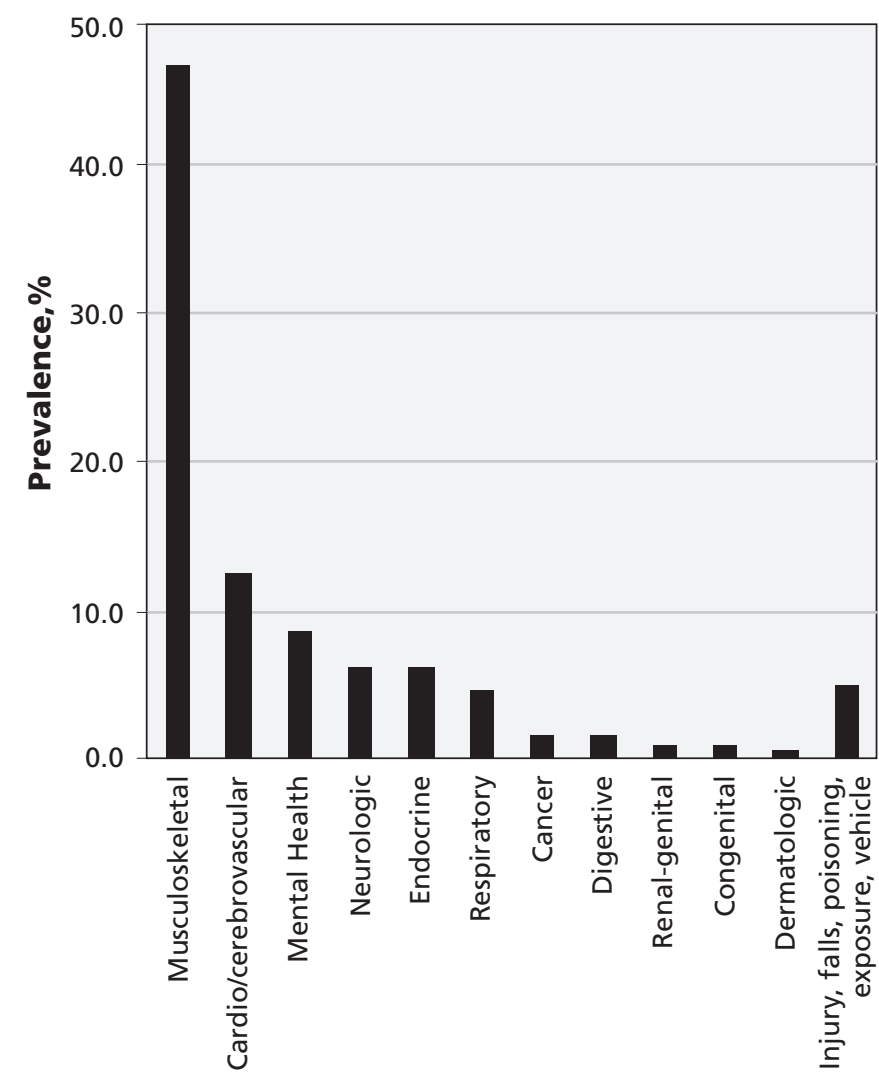

Conditions reported

Figure 1: Prevalence of self-reported conditions among adults with participation or activity limitations. The sample population is representative of 5185980 Canadian adults living with such limitations.

Table 3: The three most prevalent diagnoses in each category of conditions as reported by study participants

\begin{tabular}{|c|c|c|c|c|c|c|}
\hline \multirow[b]{2}{*}{ Rank } & \multicolumn{6}{|c|}{ Condition (ICD-10 code) } \\
\hline & Musculoskeletal & $\begin{array}{c}\text { Cardio/ } \\
\text { cerebrovascular }\end{array}$ & Mental health & Neural & Endocrine & Respiratory \\
\hline 1 & Arthritis (M13) & $\begin{array}{l}\text { Unspecified heart } \\
\text { disease, myocarditis, } \\
\text { cardiomegaly or } \\
\text { cardiovascular } \\
\text { disease (I51) }\end{array}$ & $\begin{array}{l}\text { Depressive } \\
\text { disorders (F32) }\end{array}$ & $\begin{array}{l}\text { Multiple } \\
\text { sclerosis (G35) }\end{array}$ & $\begin{array}{l}\text { Unspecified } \\
\text { diabetes mellitus } \\
\text { (E14) }\end{array}$ & Asthma (J45) \\
\hline 2 & $\begin{array}{l}\text { Dorsopathies not } \\
\text { elsewhere } \\
\text { classified, such as } \\
\text { spinal instabilities } \\
\text { or saccrococcygeal } \\
\text { disorders (M53) }\end{array}$ & Stroke (164) & $\begin{array}{l}\text { Anxiety disorders } \\
\text { (F41) }\end{array}$ & $\begin{array}{l}\text { Parkinson } \\
\text { disease (G20) }\end{array}$ & $\begin{array}{l}\text { Pure } \\
\text { hypercholesterol- } \\
\text { emia (E78) }\end{array}$ & $\begin{array}{l}\text { Unspecified } \\
\text { respiratory } \\
\text { disorders (J98) }\end{array}$ \\
\hline
\end{tabular}




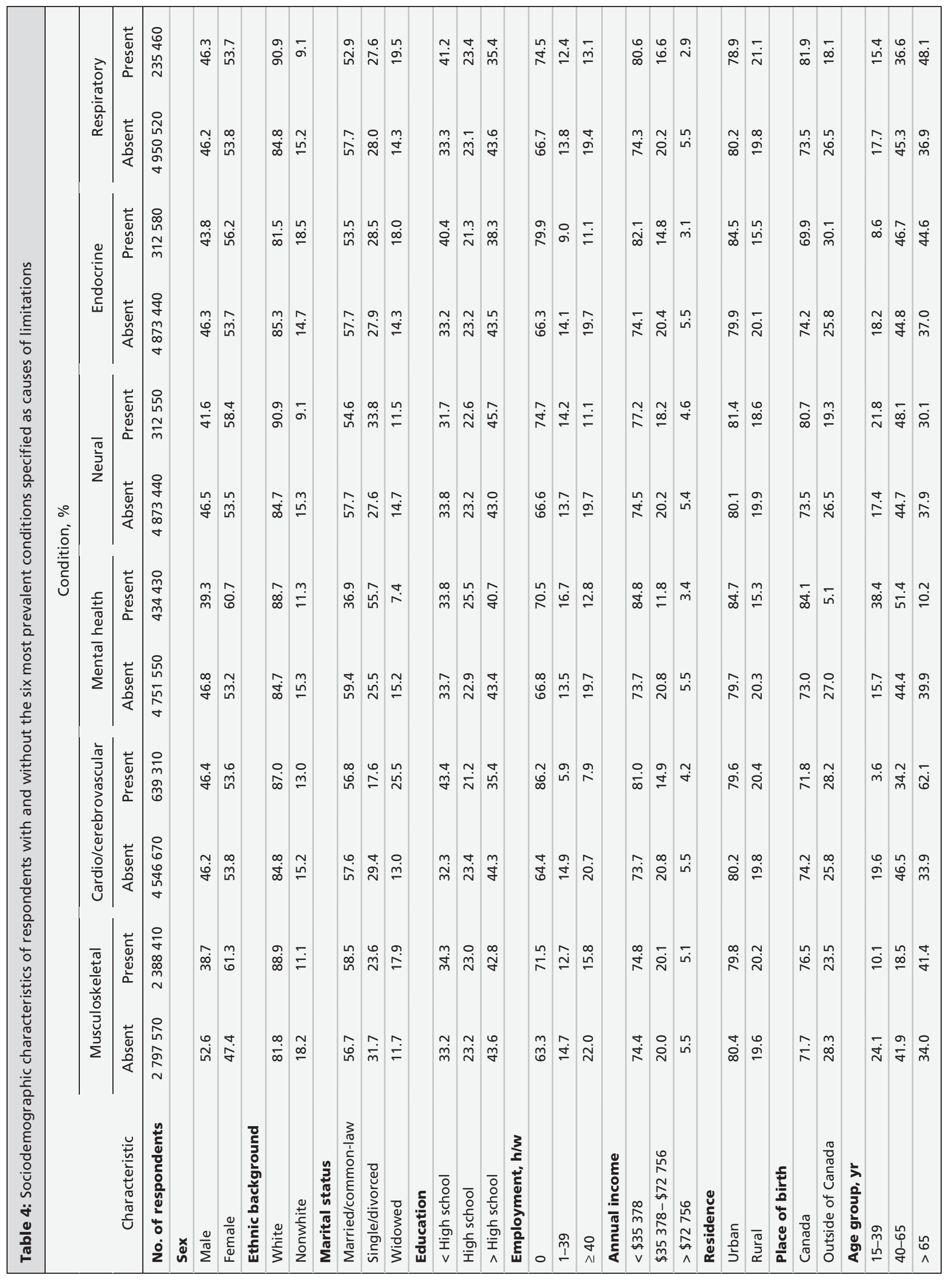


cant for respiratory disease, in the oldest age groups. In addition, there was a significant inverse association between having more than a high school education and respiratory disease in the youngest age group, which became weaker and nonsignificant as age increased (Appendix 3).

\section{Interpretation}

Musculoskeletal conditions were the most commonly reported cause of participation and activity limitations across all age groups in our study. This result parallels those of the 2005 US Survey of Income and Program Participation (SIPP) $-2,{ }^{2}$ which found arthritis or rheumatism and back or spine problems to be the most common causes of disability.

About one quarter of respondents in our study did not report causes for their limitations that could be coded using the ICD-10 system. Such nonmedical causes, such as aging, pain and losses of hearing or vision, accounted for more than half of the "health reasons" for activity restriction identified by older adults with disabilities in France. ${ }^{11}$ More than three quarters of these respondents were 40 years of age or older. However, higher proportions of people aged more than 40 years attributed their disability to medical causes versus younger people, suggesting that specific medical conditions do remain an important explanation for disability in older age groups. In addition, people aged 65 years and older were much less likely to report mental health concerns as a cause for their participation and activity limitations than were younger people.

Although attributing health problems to aging is considered inappropriate in contemporary geriatric medicine, old age is still perceived by many older adults to be a causal agent in disability. ${ }^{12,13}$ Generational differences may account for the lower likelihood of older adults attributing participation and activity limitations to mental

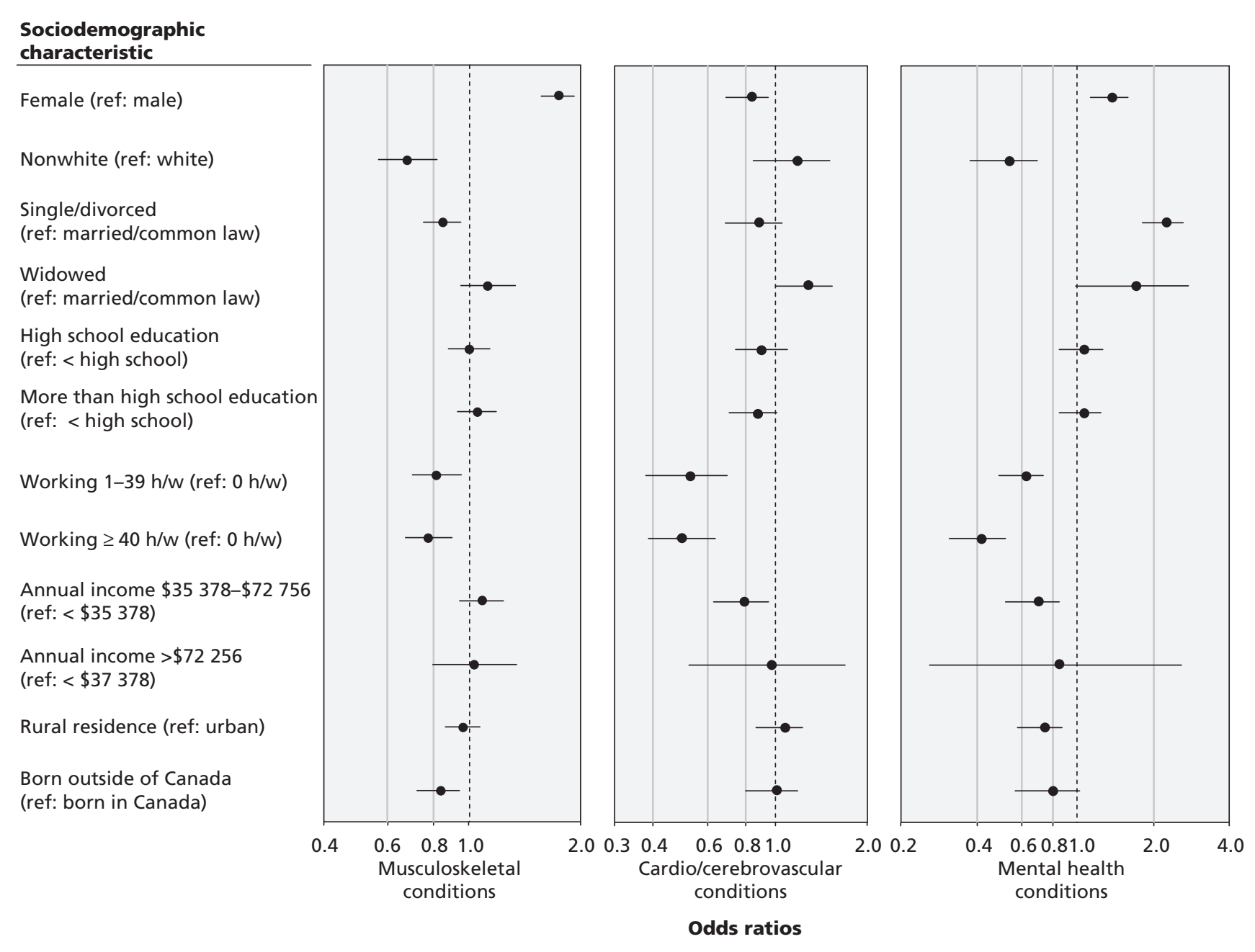

Figure 2: Adjusted associations between the sociodemographic characteristics of the respondents and the three most prevalent categories of conditions specified as causes of limitations. Error bars indicate $95 \%$ confidence intervals. Adjusted odds ratios for all six conditions categories are available in Appendix 2. 
health conditions, reflecting the stronger stigma associated with mental health disorders for older adults than for younger adults. ${ }^{14-16}$

Our results provide insight into how Canadian adults explain the causes for the participation and activity limitations with which they live. Cause is one of the components underlying cognitive representations of illness (i.e., the model a person creates to make sense of his or her illness). ${ }^{17}$ Causal attributions are post hoc interpretations that reflect a person's perceptions of the cause of a phenomenon and aid in reconstructing the basic assumptions the person has about his or her health. ${ }^{17}$

\section{Limitations}

We used broad categories of disease for this initial analysis of the Participation and Activity Limitation Survey, which may have limited the number of variables reaching statistical significance. Some people may have chosen not to disclose their participation and activity limitations and were thus excluded from the sampling frame. The overall response rate for the survey was $74.9 \%$; adults aged 20-34 years had a lower response rate of $69.2 \%$, and those 85 years and older had a response rate of $60.2 \%$. The complex sampling strategies, however, compensated for these issues.

The Participation and Activity Limitation Survey relied entirely on the self-reports of participants without clinical corroboration. No data were collected on attributed causes of limitations other than medical conditions. Furthermore, it is possible that the use of proxy respondents creates some concerns about the validity of responses. The trade-off, however, is the introduction of systematic bias by excluding a subpopulation of people with participation and activity limitations who were not able to respond to the survey themselves.

Finally, our analysis was cross-sectional and does not provide prospective, longitudinal data.

\section{Conclusion}

Our study provides collective insight as to what Canadians attribute the causes of the participation and activity limitations with which they live. A substantial number of Canadians living with participation and activity limitations attribute their disabilities primarily to medical conditions. Although it is important to recognize that some people living with participation and activity limitations wish to demedicalize their disabilities (i.e., they do not assume that medicine can or should treat, cure or prevent these conditions), ${ }^{7}$ most people do acknowledge medical conditions as a main cause of their limitations. In clinical practice, patients' beliefs about their illnesses, including the causes of their limitations, influ- ence their coping strategies and health outcomes..$^{18}$ Acknowledging and better understanding these beliefs and attitudes may assist in a patient-centred approach to care.

\section{References}

1. Participation and Activity Limitation Survey. The Daily. Ottawa (ON): Statistics Canada; 2007. Available: www.statcan.gc.ca/daily -quotidien/071203/dq071203a-eng.htm (accessed 2009 Nov. 28)

2. Centre for Disease Control. Prevalence and most common causes of disability among adults - United States, 2005. MMWR Morb Mortal Wkly Rep 2009;58:421-6.

3. Picavet HS, van den Bos GA. Comparing survey data on functional disability: the impact of some methodological differences. J Epidemiol Community Health 1996;50:86-93.

4. World Health Organization. Disability and rehabilitation WHO Action Plan 2006-2011. Geneva (Switzerland); 2006. Available: www.who.int/disabilities/publications/dar_action_plan_2006to2011 .pdf (accessed 2010 Nov. 22).

5. Verbrugge LM, Jette AM. The disablement process. Soc Sci Med 1994;38:1-14.

6. Participation and Activity Limitation Survey 2006: technical and methodological report. Ottawa $(\mathrm{ON})$ : Statistics Canada. Cat. no. 89-628-XIE.

7. Stienstra D. The intersection of disability and racelethnicity/official language/religion. 2002. Winnipeg (MB): The Canadian Centre on Disability Studies, University of Winnipeg; 2002. Available: www .canada.metropolis.net/events/Diversity/Disability_stienstra_e.pdf (accessed 2010 Mar. 4).

8. Mont S. Measuring disability prevalence. Social Protection Discussion Paper No. 0705. Washington (DC): Disability \& Development Team HDNSP. The World Bank. Available: http://siteresources .worldbank.org/DISABILITY/Resources/Data/MontPrevalence .pdf (accessed 2010 Nov. 22)

9. Wendell S. Unhealthy disabled: treating chronic illnesses as disabilities. Hypatia 2001;16:17-33.

10. Roesch SC, Weiner B. A meta-analytic review of coping with illness: do causal attributions matter? J Psychosom Res 2001;50: 205-19.

11. Ravaud JF, Letourmy A, Ville I. Identifying the population with disability: the approach of an INSEE survey on daily life and health. Population-E 2002;57:529-52.

12. Sarkisian CA, Liu H, Ensrud KE, et al. Correlates of attributing new disability to old age. Study of Osteoporotic Fractures Research Group. J Am Geriatr Soc 2001;49:134-41.

13. Valderrama-Gama E, Damian J, Ruigoma A, et al. Chronic disease, functional status and self-ascribed causes of disabilities among non-institutionalized older people in Spain. J Gerontol A Biol Med Sci 2002;57:M716-21.

14. Stephens T, Duhlberg C, Joubert N. Mental health of the Canadian population: a comprehensive analysis. Chronic Dis Can 1999;20:118-26

15. Leaf PJ, Bruce ML, Tischler GL, et al. The relationship between demographic factors and attitudes toward mental health services. J Community Psychol 1987;15:275-84.

16. Sirey JA, Bruce ML, Alexopoulos GS, et al. Perceived stigma as a predictor of treatment discontinuation in young and older patients with depression. Am J Psychiatry 2001;158:479-81.

17. Weinman J, Petrie KJ, Moss-Morris R. The Illness Perception Questionnaire: A new method for assessing the cognitive representations of illness. Psychol Health 1996;11:431-5.

Affiliations: From the Division of Respirology (Goodridge), Critical Care and Sleep Medicine, College of Medicine; the College of Medicine (Lawson, Marciniuk); and the College of Nursing (Rennie), Canadian Centre for Health and Safety in Agriculture, University of Saskatchewan, Saskatoon, Sask.

Contributors: Donna Goodridge, Josh Lawson, Darcy Marciniuk and Donna Rennie jointly conceived and designed this project and applied for access to the Participation and Activity Limitation Survey data through the Research Data Centre at the University of Saskatchewan. Josh Lawson was primarily responsible for the analysis of the data. Josh Lawson and Donna Goodridge reviewed and interpreted the results. Donna Goodridge prepared the initial draft of the manuscript, and Josh Lawson, Darcy Marciniuk and Donna Rennie provided critical feedback. All of the authors have reviewed and approved the final version of the manuscript submitted for publication. 